\title{
Twitter Sentiment Analysis during Covid -19 Pandemic
}

\author{
Dr Anjana Singh, Assistant Professor, IINTM, New Delhi, India,anjana_05@yahoo.com \\ Himanshu Tanwar, Data Scientist, New Delhi, India, himanshu.tanwar2707@gmail.com
}

\begin{abstract}
Corona virus disease is an infectious disease caused by newly discovered viruses. The epicenter of the virus was Wuhan, China and was first reported to the WHO Country Office in China on 31 December 2019. The outbreak was declared a Public Health Emergency; which is of International Concern on 30 January 2020. On 11 February 2020, WHO announced a name for the new coronavirus disease as COVID-19. It hits the world's economy drastically causing number of deaths and infections to people. People across the globe have mixed sentiments and are in the state of anxiety and fear due to the insecurity of losing loved ones. This paper is an attempt to analyze the sentiments of people during the outbreak as it has affected the lives of many in various aspects.
\end{abstract}

Keywords- Anxiety, Covid-19, Emotions, Outbreak, Sentiments.

\section{INTRODUCTION}

Corona virus disease 2019 (COVID-19) is a communicable infection which is caused by severe acute respiratory syndrome coronavirus 2 (SARS-CoV-2). This virus is closely linked to the SARS virus. The disease was first reported in Wuhan, China. The first case of the 2019-20 coronavirus pandemic in India was reported on 30 January 2020, originating from China.

The Pandemic has affected many countries across the globe including India. People are insecure and uncertain as the outbreak is declared as public health emergency. The increase of the novel coronavirus has led to a considerable disturbance of global economic activity through a decline in international production, travel, and trade. The time is very difficult for all as people hear about spread of COVID-19 from all over the world, through television, social media, newspapers, family and friends and other sources. The most common emotion faced by all individual is Fear when there is negativity all around. It makes people anxious, panicky and can even make people think, say or do things that are not consider appropriate under usual state of affairs. In view of the spread of virus many countries announces lockdowns and our Honorable Prime Minister Narendra Modi announced a nation-wide lock down urging citizens with folded hands to follow the directives to prevent further spread.

\section{OBJECTIVE}

The objective of the study is to find out people's disposition during the coronavirus outbreak and their sentiments during the situation which is highly uncertain and unpredictable.

\section{METHODOLOGY}

The data is taken from Twitter (\#Covid19\#Coronavirus) and total of 10,000 tweets are into consideration to find out the emotion, state and sentiments of people. The Data is being analyzed using 'RStudio' and is presented with the help of a cloud, graphs and tables.

The flow of the analysis is as follows:

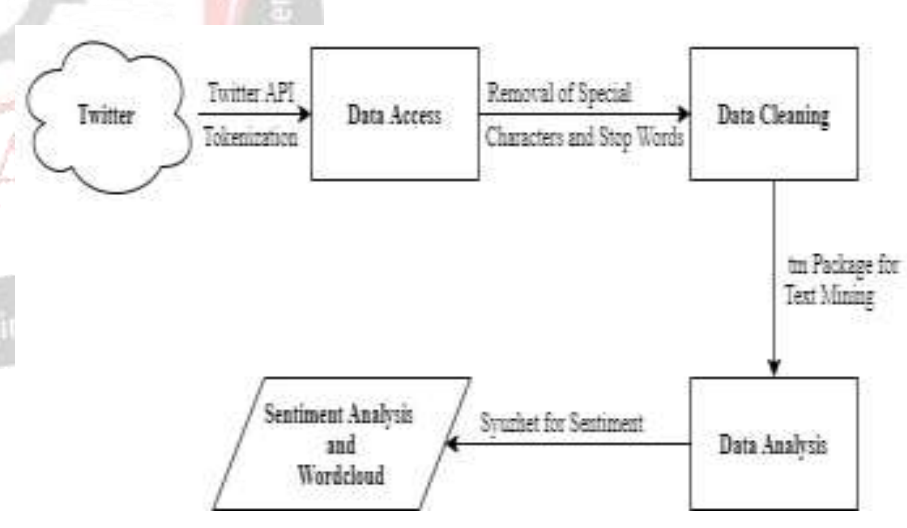

Twitter has made the assignment of examining tweets posted by users simpler by building up an API which individuals can use to extricate tweets and hidden metadata. This API helps us extract twitter data in a very structured format which can then be cleaned and processed further for analysis. Once we created an API using Twitter Developer option, Twitter provides consumer key (API Key), Consumer Secret (API Secret),Access Token, Access Token Secret. Extracting Tweets using Twitter API after that data cleansing being done like removal of special characters and stop words using the library "tm" which is majorly used for text mining. After cleansing the data, corpus of word is being created and corpus is nothing but a collection of documents which is used to create a word cloud and then evaluating the sentiments of the people which was created 
by using the library "syuzhet" and it contains the in-built function called "get_nrc_sentiment".

\section{ANANLYSIS \& INTERPRETATION}

Top 15 tweets words are taken into consideration for the formation of the wordcloud and during the outbreak the crisis is one of the top word which was used by the people across the globe in their tweets. Health, Press, Cases, Pandemic, issues etc were also used frequently by the people in their tweets. The cloud is showing the top words in the tweets using \#coronavirus and \# covid19.

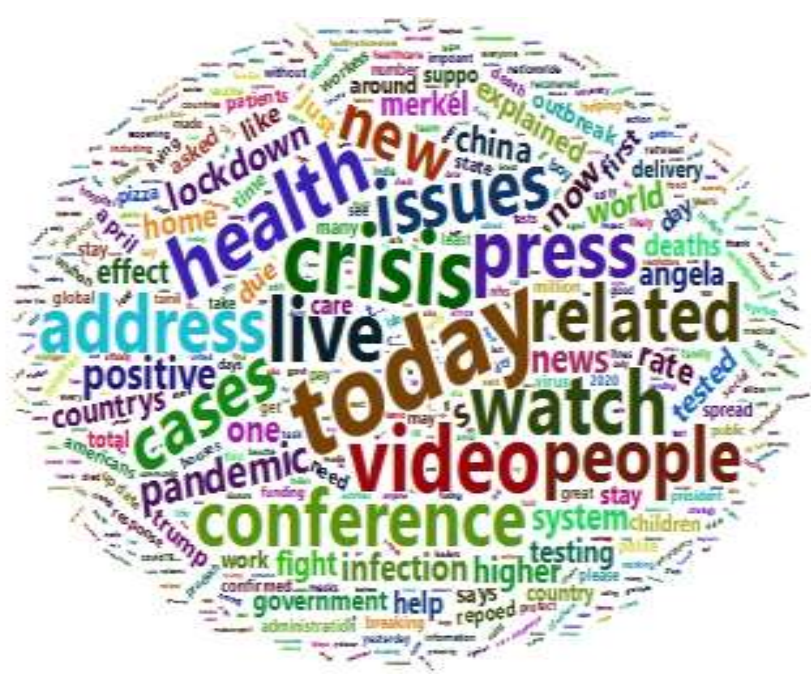

Fig 1- Cloud SHOWING THE TWEets

\begin{tabular}{|c|c|}
\hline Word & Frequency \\
\hline Today & 916 \\
\hline Crisis & 792 \\
\hline Video & 708 \\
\hline Live & 683 \\
\hline Watch & 682 \\
\hline Health & 678 \\
\hline Press & 643 \\
\hline Conference & 613 \\
\hline Issues & 612 \\
\hline Related & 612 \\
\hline Cases & 606 \\
\hline Address & 605 \\
\hline People & 595 \\
\hline New & 555 \\
\hline Pandemic & 355 \\
\hline
\end{tabular}

TABLE 1- SHOWING THE FREQUENCY OF DIFFERENT WORDS

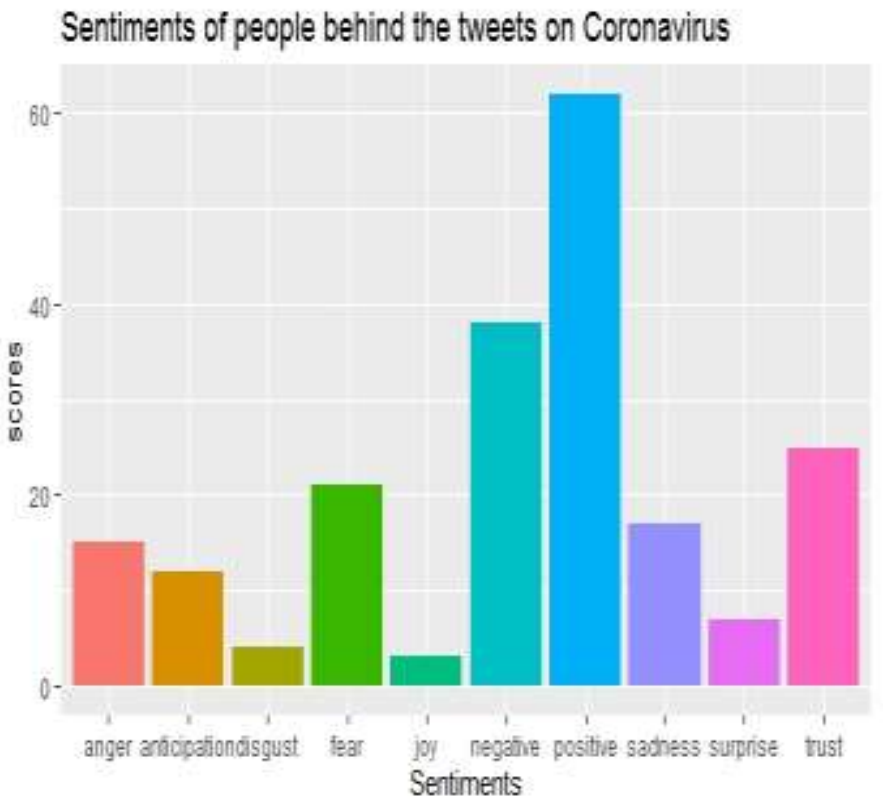

FIG 2- GRAPHS SHOWING THE VARIOUS EMOTIONS

\begin{tabular}{|c|c|}
\hline Sentiment & Score \\
\hline Positive & 62 \\
\hline Negative & 38 \\
\hline Trust & 25 \\
\hline Fear & 21 \\
\hline Sadness & 17 \\
\hline Anger & 15 \\
\hline Anticipation & 12 \\
\hline Surprise & 7 \\
\hline Disgust & 4 \\
\hline Joy & 3 \\
\hline
\end{tabular}

TABLE 2- SHOWING THE SCORE OF DIFFERENT EMOTIONS

According to the analysis ; People across the globe are exhibiting different emotions/sentiments during the outbreak. According to library available in $\mathrm{R}$ which is "syuzhet" has available function called get_nrc_sentiment; the top emotion which the people are showing is positive as the score is 62 and are hoping that everything would get well soon and they will return to normalcy which is a good sign for the world. People are sure that their life will be smooth and they have faith in god as well as in the system. Certain amount of population is negative and is afraid of the pandemic and loosing trust as the score is 38 . Trust is third in the list and the score is 25 which indicate that in the period of uncertainty people are holding trust. Apart from it people have mixed emotions of anger, fear, surprise, anticipation etc. Joy holds the last position and the score is 3 which indicate the stress and anxiety among people.

\section{Conclusion}

Covid-19 brings various sentiments among people. According to the analysis majority of the population is positive across the globe and is expecting that things will get back to track soon which shows a good sign for all to 
fight the pandemic. The world's population is together and is fighting the situation with positivity.

People are displaying mixed sentiments of trust, negativity, fear, anxiety and stress. As per the score positivity is at the highest and joy is at lowest position which shows the feeling of insecurity among people. The population across the globe is hoping to come out soon from this uncertain situation.

\section{REFERENCES}

[1] "Coronavirus Disease (COVID-19) - events as they happen", Who.int,2020.[Online].Available:https://www .who.int/emergencies/diseases/novel-coronavirus-

2019/events-as-they-happen. [Accessed: 10- Apr2020].

[2] "Coronavirus disease 2019", En.wikipedia.org, 2020. [Online].Available:https://en.wikipedia.org/wiki/Coron avirus_disease_2019. [Accessed: 11- Apr- 2020].

[3] Coronavirus Disease 2019 (COVID-19)", Centers for Disease Control and Prevention, 2020. [Online]. Available: https://www.cdc.gov/coronavirus/2019ncov/daily-life-coping/managing-stress-anxiety.html. [Accessed: 27- Apr- 2020].

[4] D. Robson, "The fear of coronavirus is changing our psychology", Bbc.com, 2020. [Online]. Available: https://www.bbc.com/future/article/20200401-covid19-how-fear-of-coronavirus-is-changing-ourpsychology. [Accessed: 12- Apr- 2020].

[5] "Fear can spread from person to person faster than the coronavirus - but there are ways to slow it down", The Conversation, 2020. [Online]. Available: https://theconversation.com/fear-can-spread-fromperson-to-person-faster-than-the-coronavirus-but-thereare-ways-to-slow-it-down-133129. [Accessed: 12- Apr2020].

[6] "\#IndiaFightsCorona COVID-19", MyGov.in, 2020. [Online]. Available: https://www.mygov.in/covid-19. [Accessed: 10- Apr- 2020].

[7] M. Weber, "Coronavirus Anxiety: Coping with Stress, Fear, and Worry", HelpGuide.org, 2020. [Online]. Available:https://www.helpguide.org/articles/anxiety/co ronavirus-anxiety.htm. [Accessed: 12- Apr- 2020].

[8] 2020. [Online]. Available: https://www.who.int/healthtopics/coronavirus\#tab=tab_1. [Accessed: 11- Apr2020]. 